\title{
Lung inflammation by fungus, Bjerkandera adusta isolated from Asian sand dust (ASD) aerosol and enhancement of ovalbumin-induced lung eosinophilia by ASD and the fungus in mice
}

Boying Liu ${ }^{1,2,8}$, Takamichi Ichinose ${ }^{2 *}$, Miao He ${ }^{1,2}$, Fumihisa Kobayashi ${ }^{3}$, Teruya Maki ${ }^{3}$, Seiichi Yoshida ${ }^{2}$, Yasuhiro Yoshida ${ }^{4}$, Keiichi Arashidani ${ }^{4}$, Hirohisa Takano ${ }^{5}$, Masataka Nishikawa ${ }^{6}$, Guifan Sun ${ }^{1}$

and Takayuki Shibamoto ${ }^{7}$

\begin{abstract}
Background: Bjerkandera adusta (B. adusta) is one of the most important etiological fungi associated with chronic cough. However, precise details of the inflammatory response to exposure are not well understood yet. B. adusta was recently identified in Asian sand dust (ASD) aerosol. Therefore, in the present study the exacerbating effects of ASD on B. adusta-induced lung inflammation and B. adusta + ASD on ovalbumin (OVA)-induced murine lung eosinophilia were investigated using experimental mice.

Methods: In order to prepare testing samples, B. adusta obtained from ASD aerosol was inactivated by formalin and ASD collected from the atmosphere was heated to remove toxic organic substances (H-ASD). CD-1 mice were instilled intratracheally with 12 different samples prepared with various combinations of B. adusta, H-ASD, and OVA in a normal saline solution. The lung pathology, cytological profiles in bronchoalveolar lavage fluid (BALF), and the levels of inflammatory cytokines/chemokines in BALF were investigated.
\end{abstract}

Results: H-ASD aggravated the lung eosinophilia induced by B. adusta alone, which also aggravated the lung eosinophilia induced by OVA. The mixture of OVA, H-ASD, and B. adusta caused serious fibrous thickening of the subepithelial layer, eosinophil infiltration, and proliferation of goblet cells in the airways along with remarkable increases of IL-13, eotaxin, IL-5, and MCP-3 in BALF.

Conclusions: The results of the present study demonstrated that $B$. adusta isolated from ASD aerosol induces allergic lung diseases. H-ASD enhanced allergic reactions caused by OVA or B. adusta. A mixture of B. adusta, $\mathrm{H}-\mathrm{ASD}$, and OVA caused the most remarkable exacerbation to the allergic airway inflammation via remarkable increases of pro-inflammatory mediators.

Keywords: Asian sand dust, Bjerkandera adusta, Fungus, Lung eosinophilia, Asthma

\footnotetext{
* Correspondence: ichinose@oita-nhs.ac.jp

${ }^{2}$ Department of Health Sciences, Oita University of Nursing and Health

Sciences, 870-1201 Oita, Japan

Full list of author information is available at the end of the article
} 


\section{Background}

Bjerkandera adusta (B. adusta) is known to occur throughout the world. This fungus produces abundant asexual spores, so-called arthroconidia, from the hyphae [1]. The asexual spores are known to be a fungal aeroallergen, which causes an allergic fungal cough [2]. Therefore, this fungus is one of the most significant etiological fungus-associated chronic cough (FACC) [1]. However, it is not well understood yet what type of inflammatory response is initiated in the lungs of human with exposure to components in $B$. adusta or infection caused by B. adusta.

Asian sand dust (ASD) storms arise from the dry and semi-arid areas of southern Mongolia and Northeast China. ASD is transported to East China, the Korean Peninsula, and Japan. It even travels across the Pacific Ocean to reach the United States [3,4]. Recently, $B$. adusta was identified in ASD aerosol, which was collected from the atmosphere in Suzu, Japan during the occurrence of an Asian dust event [5]. Many patients with FACC have been reported in Kanazawa (near Suzu City) [1]. Above all, ASD events have been known to exacerbate asthma for adults and children in Japan [6,7]. However, the role of ASD events in the occurrence of these diseases (FACC, asthma) is not well understood yet. It is crucial to investigate the effects of $B$. adusta and ASD on airway diseases in order to find the relevant treatment for patients of FACC or asthma.

In the present study, the exacerbating effects of ASD on B. adusta-induced lung inflammation and fungus and/or ASD on ovalbumin (OVA)-induced lung eosinophilia were investigated using a mouse model of asthma.

\section{Materials and methods}

Animals

A total of 168 male CD-1 mice (5 weeks of age) were purchased from Charles River Japan Inc. (Kanagawa, Japan). The abnormal or unhealthy mice were removed after one week and the remaining healthy mice were used at 6 weeks of age. The mice were fed commercial diet CE-2 (CLEA Japan Inc., Tokyo, Japan) and given water ad libitum. The mice were housed in plastic cages lined with soft wood chips. The cages were placed in a conventional room, which was air conditioned at $23^{\circ} \mathrm{C}$ and $55-70 \%$ humidity with a light/dark (12 h/12 h) cycle. CD-1 male mice were used because of their moderate responsiveness to airway inflammation caused by OVA [8]. The present study adhered to the U.S. National Institutes of Health guidelines for the use of experimental animals. The animal care method was approved by the Animal Care and Use Committee at Oita University of Nursing and Health Sciences, Oita, Japan.

\section{Preparation of particle samples}

ASD was collected from the atmosphere using a highvolume air sampler with a Teflon filter at the University of Occupational and Environmental Health, Kitakyushu, Fukuoka, Japan during May $1^{\text {st }}-3^{\text {nd }}, 2011$ right after a massive 3-day dust storm event occurred in East Asia. The flow rate for collection was $770 \mathrm{~L} / \mathrm{min}$. The instrumental classification size (defined as the $50 \%$ cut-off size of the aerodynamic diameter) was $5.9 \mu \mathrm{m}$ in the 1st stage, $2.8 \mu \mathrm{m}$ in the 2nd stage, $1.7 \mu \mathrm{m}$ in the 3rd stage, $0.91 \mu \mathrm{m}$ in the 4th stage, and $<0.91 \mu \mathrm{m}$ of back-up. The size distribution peak of ASD was at $3.8 \mu \mathrm{m}$. The density ranges of the ambient particulate matter measured by LIDAR (Light Detection and Ranging) on May $1^{\text {st }}-3^{\text {rd }}$, 2011 were $350-550 \mu \mathrm{g} / \mathrm{m}^{3}$ in Nagasaki (Nagasaki Prefectural Institute of Public Health and Environmental Science), Japan.

The particle samples in a glass bottle were heated at $360^{\circ} \mathrm{C}$ for $30 \mathrm{~min}$ in an electric heater to remove toxic materials (microbiological materials, sulfate, nitrate, etc.) and labelled as H-ASD.

\section{Fungus preparation}

The aerosol samples-collected at $400 \mathrm{~m}$ above the ground using a tethered balloon equipped with an aerosol sampler on May 7, 2008 in Suzu, Ishikawa Prefecture-were inoculated onto four culture agar plates (nutrient agar, blood agar, potato dextrose agar, and Sabouraud dextrose agar). After a few days of incubation, several microbial colonies on the agar plates were transferred to new agar plates. A total of 8 isolates were obtained. The $18 \mathrm{~S}$ rRNA gene (ca. $1650 \mathrm{bp}$ ) and the internal transcribed spacer (ITS) region (ca. $620 \mathrm{bp}$ ) of the fungal isolate were sequenced and compared with known sequences from the DDBJ database. Sequences of the isolate were the most closely related to B. adusta (similarities: > 99.9\%). The fungal isolate was also confirmed as $B$. adusta by microscopic observation [5].

The density ranges of the asexual spore (4-5 $\mu \mathrm{m}$ size) in the atmosphere of Suzu City during dust storm event (May $1^{\text {st }}-3^{\text {rd }}, 2011$ ) were about 1 million -6 million particles $/ \mathrm{m}^{3}$, which were remarkably higher than the general levels (about 5000 particles $/ \mathrm{m}^{3}$ ) [9]. The asexual spores may cause adverse effect to the health. Because $B$. adusta produces asexual spores from the hyphae, the fungal hyphae were used in this study.

The fungal hyphae cultivated were inactivated with $1 \%$ formalin for 1 day at $4^{\circ} \mathrm{C}$ according to the vaccine manufacture method with slight modifications [10]. Briefly, the inactivated $B$. adusta solution was centrifuged at $1200 \mathrm{rpm}$ for $10 \mathrm{~min}$. The resulting pellet was suspended in a normal saline solution (Otsuka Co., Kyoto, Japan) and then the suspension was sonicated for $1 \mathrm{~min}$ with a UD-201 type ultrasonic disrupter with micro tip (Tomy, Tokyo, Japan) under cooling conditions. The suspension was centrifuged at $12,000 \mathrm{rpm}$ for $10 \mathrm{~min}$ 5 times using a normal saline solution. The resulting 
supernatant was removed and the residual materials were dried under reduced pressure.

\section{Analysis of LPS and $\beta$-glucan in H-ASD and B. adusta} The contents of LPS and $\beta$-glucan in H-ASD and $B$. adusta were measured by a kinetic assay using Endospec ES-24S set (Seikagaku Corp., Tokyo, Japan) for LPS activity and Glucatell Kit (Associates of Cape Cod. Inc., MA, USA) for $\beta$-glucan activity. The experiments were performed according to the manuals provided by the manufacturers. Briefly, approximately $5 \mathrm{mg}$ of $\mathrm{H}$-ASD or $10 \mu \mathrm{g}$ of $B$. adusta (dry weight) was suspended in $1 \mathrm{~mL}$ water (LPS and $\beta$-glucan free; Seikagaku Corp., Tokyo, Japan) and then allowed to stand at room temperature for $2 \mathrm{~h}$. LPS and $\beta$-glucan concentrations in the supernatants were determined using a Pyro Color-MP:Chromogenic Diazo-Coupling Kit (Associates of Cape Cod. Inc., MA, USA). The detection limits for LPS and $\beta$-glucan were $0.001 \mathrm{EU} / \mathrm{ml}$ and $2 \mathrm{pg} / \mathrm{ml}$, respectively.

\section{Study protocol}

Experimental mice were divided into twelve groups $(\mathrm{n}=$ 14 per group) and each group was treated with a specific testing sample. The 12 testing samples $(0.1 \mathrm{~mL}$ each of $0.9 \% \mathrm{NaCl}$ normal saline solution) prepared for the present study were control (containing normal saline alone); H-ASD (0.1 mg H-ASD alone); B.ad 2 (2 $\mu \mathrm{g} \mathrm{B.}$ adusta alone); B.ad 8 (8 $\mu \mathrm{g}$ B. adusta alone); H-ASD + B.ad 2 (0.1 mg H-ASD and $2 \mu \mathrm{g} \mathrm{B.} \mathrm{adusta);} \mathrm{H-ASD} \mathrm{+} \mathrm{B.}$ ad 8 (0.1 mg H-ASD and $8 \mu \mathrm{g}$ B. adusta); OVA alone $(1 \mu \mathrm{g})$; OVA + H-ASD (1 $\mu \mathrm{g}$ OVA and $0.1 \mathrm{mg}$ H-ASD); OVA + B.ad $2(1 \mu \mathrm{g}$ OVA and $2 \mu \mathrm{g}$ B. adusta $) ; \mathrm{OVA}+B$. ad $8(1 \mu \mathrm{g}$ OVA and $8 \mu \mathrm{g} \mathrm{B.} \mathrm{adusta);} \mathrm{OVA} \mathrm{+} \mathrm{H-ASD}+B$. ad 2 (1 $\mu \mathrm{g}$ OVA, $0.1 \mathrm{mg} \mathrm{H}-\mathrm{ASD}$, and $2 \mu \mathrm{g} \mathrm{B}$. adusta); and OVA + H-ASD + B.ad 8 (1 $\mu \mathrm{g}$ OVA, $0.1 \mathrm{mg} \mathrm{H}-\mathrm{ASD}$, and $8 \mu \mathrm{g} \mathrm{B}$. adusta). One previous report indicated that the microbe was present in ASD aerosol at approximately $10 \%$ [11]. The instillation dose of $B$. adust was set at $2 \%(2 \mu \mathrm{g})$ and $8 \%(8 \mu \mathrm{g})$ for the one-time ASD instillation dose $(0.1 \mathrm{mg})$, because one kind of microbial species was not considered to occupy $10 \%$ of total microbe in ASD aerosol. The one-time ASD instillation dose $(0.1 \mathrm{mg})$ was conducted according to a previously reported method [12].

B. adusta, H-ASD, and OVA were suspended in a normal saline solution (Otsuka Co., Kyoto, Japan) and sonicated for 5 min with ultrasonic disrupter Model UD-201 with micro tip (Tomy, Tokyo, Japan) under cooling conditions. A $0.1 \mathrm{~mL}$ saline solution containing the samples described above was intratracheally instilled to the mice through a polyethylene tube under anesthesia with $4 \%$ halothane (Takeda Chemical, Osaka, Japan) four times at 2-week intervals. One day after the last administration, the mice from all groups were killed by exsanguination under deep anesthesia by intraperitoneal injection of pentobarbital.

The mice in each group (14 mice) were divided into two sub-groups. The first (6 mice) was used for pathological evaluation. The remaining 8 mice were used for the analysis of cytokine and chemokine in the bronchoalveolar lavage fluids (BALFs).

\section{Pathological evaluation and BALF preparation}

The lungs were fixed by a $10 \%$ neutral phosphate-buffered formalin solution. After separation of the lobes, blocks ( $2 \mathrm{~mm}$ thickness) were taken for paraffin embedding. The embedded blocks were sectioned ( $3 \mu \mathrm{m}$ thickness) and then stained with periodic acid-schiff (PAS) to evaluate the degree of proliferation of goblet cells in the bronchial epithelium and thickening of the subepithelial layer in the main bronchus. The sections were also stained with hematoxylin and eosin $(H \& E)$ in order to evaluate the degree of infiltration of eosinophils or lymphocytes in the airway from proximal to distal $[12,13]$.

A pathological analysis of the inflammatory cells and epithelial cells in the airways of each lung lobe on the slides was performed using a Nikon ECLIPSE light microscope (Nikon Co., Tokyo, Japan). The degree of proliferation of goblet cells in the bronchial epithelium was graded on the following scale: 0 , not present; 1 , slight; 2 , mild; 3 , moderate; 4, moderate to marked; and 5, marked. 'Slight' was defined as less than $20 \%$ of the airway having goblet cells stained with PAS; 'mild' as $21-40 \%$; 'moderate' as $41-$ $60 \%$; 'moderate to marked' as $61-80 \%$; and 'marked' as more than $81 \%[12,13]$. The degree of thickening of the subepithelial layer in the main bronchus was graded on the following scale: 0 , not present; 1 , slight; 2 , mild; 3 , moderate; 4 , moderate to marked; and 5 , marked. 'Slight' was defined as $5-12 \mu \mathrm{m}$ of the main bronchus with fibroblasts stained with PAS; 'mild' as $13-20 \mu \mathrm{m}$; 'moderate' as $21-$ $28 \mu \mathrm{m}$; 'moderate to marked' as $29-36 \mu \mathrm{m}$; and 'marked' as more than $37 \mu \mathrm{m}$ [13].

Pathological changes were assessed on one slide stained with PAS per mouse. This evaluation procedure was performed by two pathologists who cross-checked the data with blinded specimens. The values were mean \pm SE $(n=6)$.

BALF preparation and cell counts were conducted according to a previously reported method $[12,13]$. The total amount of the lavages collected from individual mice was measured for the protein levels of cytokines and chemokines in BALF. The total cell counts of each fresh fluid specimen were determined using a hemocytometer.

\section{Quantitation of cytokines and chemokines in BALFs}

The cytokine protein levels in the BALF were determined using ELISA. IL-5 and IL-12 were measured using an ELISA kit from Thermo Scientific (Rockford, 
IL, USA). MCP-3 was measured using an ELISA kit from Bioscience (San Diego, CA, USA). KC, MCP-1, MIP-1 $\alpha$, RANTES, TNF- $\alpha$, Eotaxin, IFN- $\gamma$, TGF- $\beta 1$, IL- $1 \beta$, IL-4, IL-6, IL-10, IL-13, and IL-33 were measured with an ELISA kit from R\&D Systems (Minneapolis, MN). These cytokines and chemokines were measured by individual ELISA kit.

\section{Measurement of antigen-specific $\lg \mathrm{G} 1$ and $\lg \mathrm{E}$ antibodies} OVA-specific immunoglobulin E (IgE) and IgG1 antibodies were measured using a Mouse OVA-IgE ELISA kit and a Mouse OVA-IgG1 ELISA kit (Shibayagi, Shibukawa, Japan). The absorption at $450 \mathrm{~nm}$ (sub-wavelength, $620 \mathrm{~nm}$ ) for OVA-specific IgE and IgG1 antibody was measured using a microplate reader (Spectrafluor; Tecan, Salzburg, Austria).

\section{Statistical analysis}

Statistical analyses of the pathologic evaluations of the airway, cytokine and chemokine proteins in BALF were conducted using the Tukey Test for Pairwise Comparisons (KyPlot Ver.5, Kyens Lab Inc., Tokyo, Japan). Differences among groups were determined as statistically significant at a level of $\mathrm{p}<0.05$.

\section{Results}

Contents of LPS and $\beta$-glucan in H-ASD and $B$. adusta

LPS and $\beta$-glucan were not detected in the H-ASD samples. The $\beta$-glucan content in $B$. adusta was $32.8 \mathrm{ng} / \mathrm{mg}$. LPS was not detected in B. adusta.

\section{Enhancement of cell numbers in BALF by $B$. adusta and $\mathrm{H}-\mathrm{ASD}$}

Figure 1 shows the numbers of macrophages, neutrophils, eosinophils, and lymphocytes determined in BALF from the control and treated groups. The significant increase of these BAL cells was resulted by B.ad 8 alone, $\mathrm{H}$-ASD + B.ad 2/B.ad 8, OVA + B.ad 2/B.ad 8, and OVA + $\mathrm{H}-\mathrm{ASD}+$ B.ad 2/B.ad 8. Numbers of BAL cells, especially neutrophils and eosinophils of all substances increased dose relatively by $B$. adusta. In particular, significant effects by the addition of B.ad 8 were observed in neutrophils and eosinophils. Overall, H-ASD played an important role in the enhancement of inflammatory cells in BALF.

On the other hand, OVA + H-ASD + B.ad 2 and OVA + $\mathrm{H}$-ASD + B.ad 8 significantly decreased eosinophil numbers compared with H-ASD + B.ad 2 and H-ASD + B.ad 8, suggesting that OVA inhibits the action of $B$. adusta toward eosinophil in BALF.

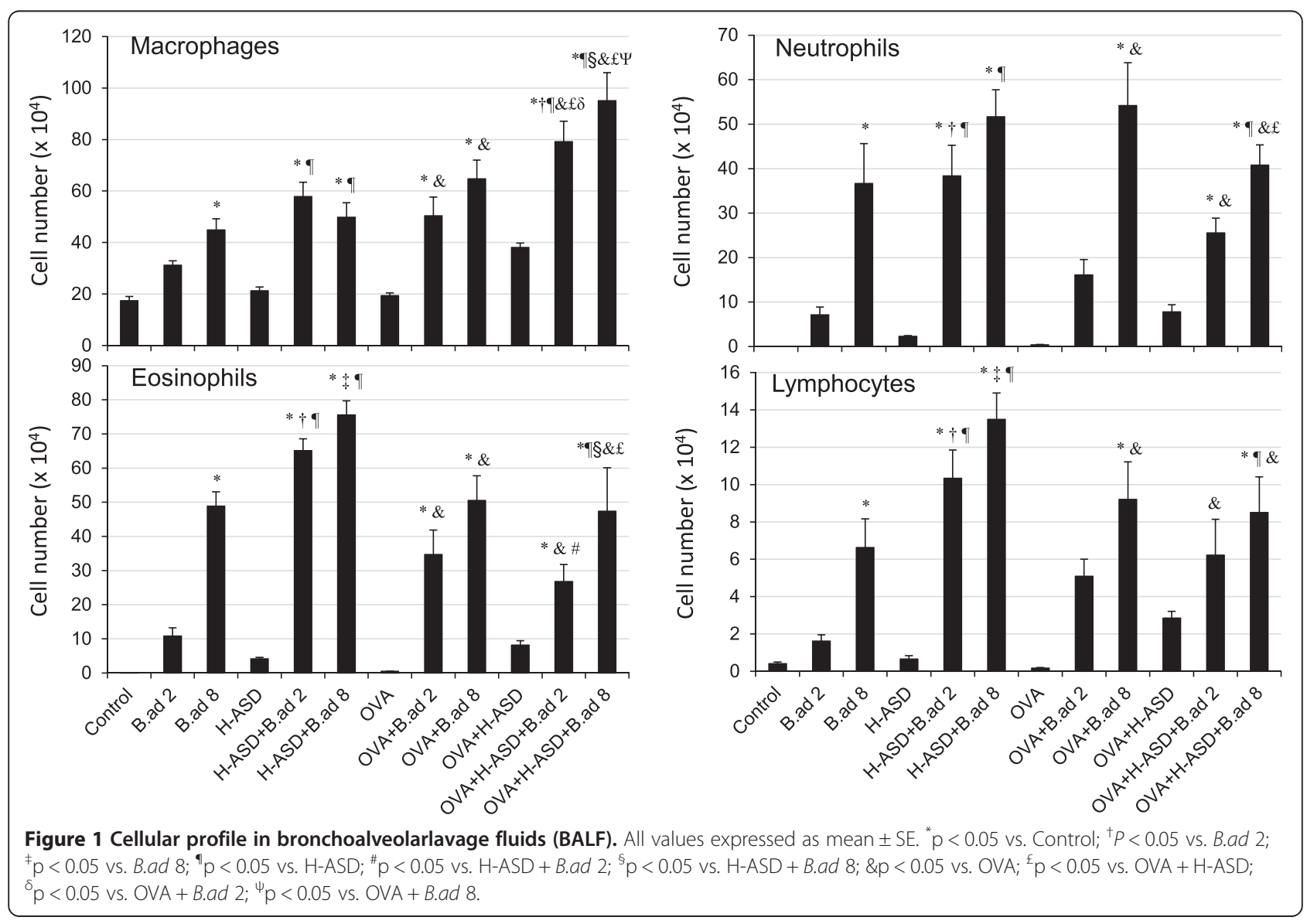




\section{Enhancement of pathologic changes in the airway by $\mathrm{H}-\mathrm{ASD}$ and $B$. adusta}

Figure 2 shows the pathological changes caused by the particle samples in the murine airway. Figures 3 (PAS stain) and 4 (HE stain) show the effects of H-ASD and B. adusta on pathological changes in the lungs. No pathologic alteration was observed in the lungs of the control (A in Figures 3 and 4). Effects by particle samples exhibited results similar to the case of cell numbers in BALF. Exposure to B.ad 8 alone (B in Figure 3) resulted in a significant increase in proliferation of goblet cells, infiltration of eosinophils, and lymphocytes in the submucosa of the airway compared with the control (refer to Figure 2), and caused fibrous thickening of the subepithelial layer in the airway (B in Figure 3). H-ASD alone ( $\mathrm{C}$ in Figures 3 and 4 ) or OVA alone ( $\mathrm{E}$ in Figures 3 and 4) caused only slight proliferation of bronchial cells and infiltration of macrophages in the alveoli but no change of infiltration of eosinophils.

When B.ad 2 or B.ad 8 was mixed with H-ASD, proliferation of goblet cells in the airway epithelium and infiltration of eosinophils and lymphocytes in the submucosa of the airway and fibrous thickening of the subepithelial layer in the airway were observed ( $D$ in Figures 3 and 4). These pathological changes in the $\mathrm{H}$ $\mathrm{ASD}+$ B.ad 8 group were greater than in the $\mathrm{H}-\mathrm{ASD}+$ B.ad 2 group (Figure 2).

When B.ad 2 was added to OVA, mild proliferation of goblet cells in the airway epithelium and infiltration of eosinophil and lymphocytes in the submucosa along with mild fibrous thickening of the subepithelial layer in the airway were recognized. A further increase of these pathological changes ( $F$ in Figures 3 and 4) was observed by the addition of B.ad 8 compared with OVA + B.ad 2 . These changes were significant compared with the control and OVA alone (Figure 2).

OVA + H-ASD caused mild pathological alterations ( $G$ in Figures 3 and 4), whereas the addition of B.ad 2 increased pathological changes such as mild to moderate goblet cell proliferation, eosinophil infiltration, and accumulation of lymphocyte in the submucosa of airway compared with the control, B.ad 2, H-ASD, and OVA. As shown in Figure 2, the addition of B.ad 8 caused the greatest increase of four items in pathological changes ( $\mathrm{H}$ in Figures 3 and 4) compared with the control and promoted a serious fibrous thickening in the airway

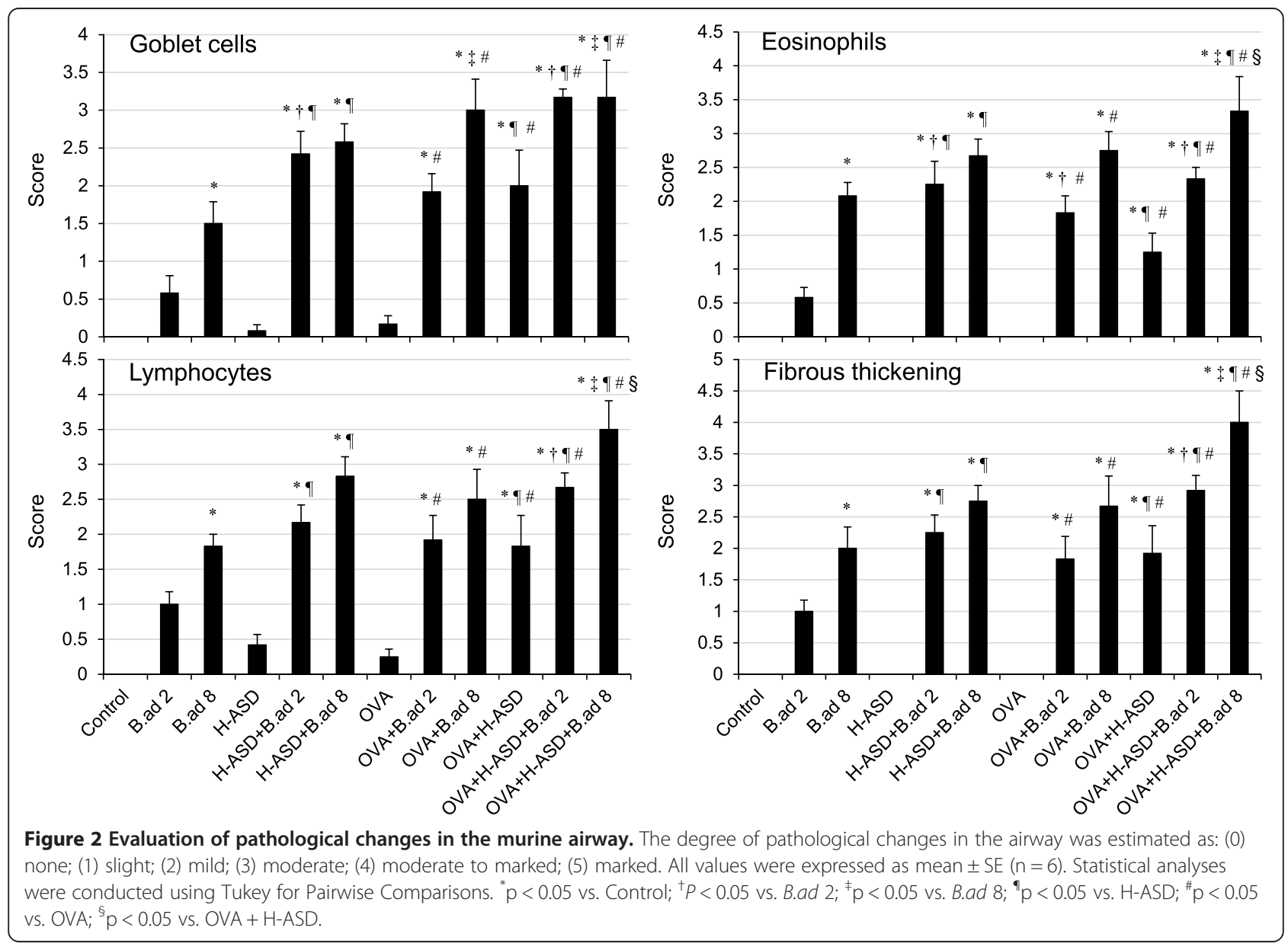




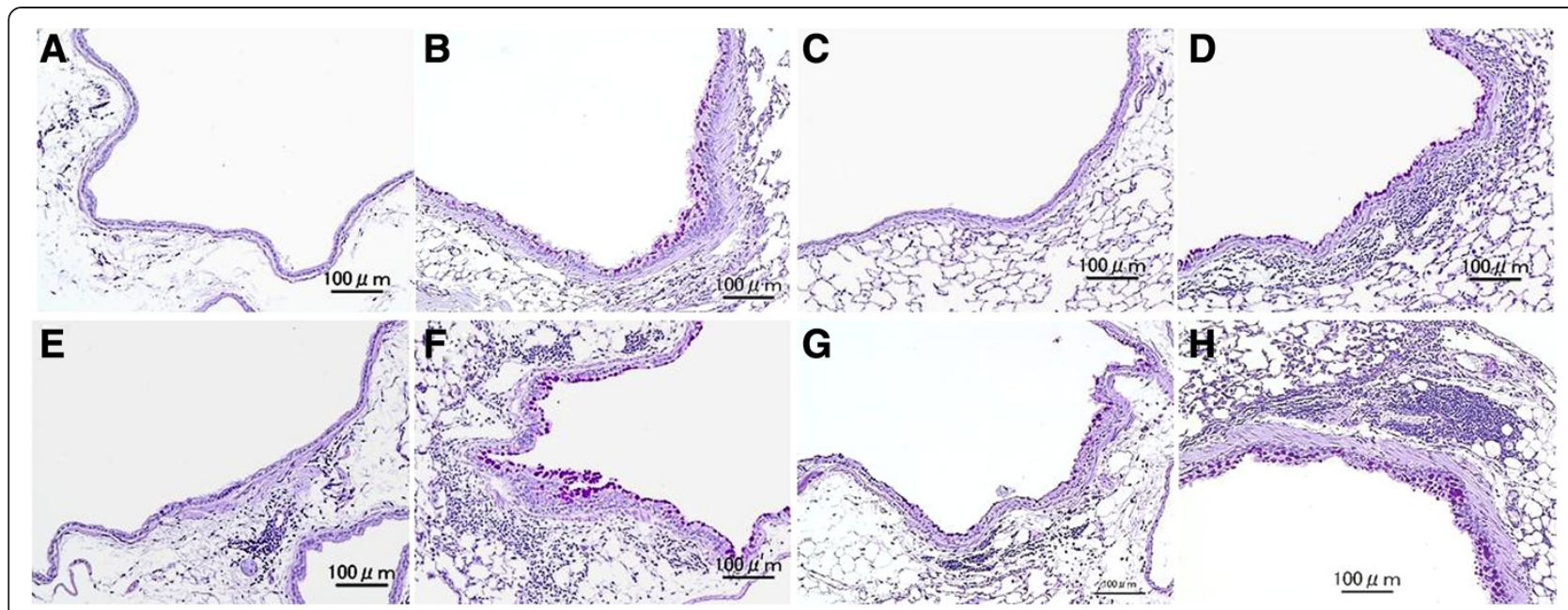

Figure 3 Effects of testing samples on pathological changes in the lungs. No pathologic alterations were seen in the lungs of the control (A). Mild proliferation of goblet cells that have mucus stained pink with PAS in airway epithelium and moderate fibrous thickening of the subepithelial layer in the airway exposed to B.ad 8 alone (B). Very slight proliferation of bronchial cells exposed to H-ASD alone (C). Mild proliferation of goblet cells that have mucus stained pink with PAS in the airway epithelium and infiltration of inflammatory cells in the submucosa of airway and mild fibrous thickening of the subepithelial layer in the airway exposed to H-ASD + B.ad 8 (D). Very slight proliferation of goblet cells in the airway epithelium and slight infiltration of inflammatory cells in the submucosa of airway exposed to OVA alone (E). Mild to moderate proliferation of goblet cells in the airway epithelium and infiltration of inflammatory cells in the submucosa of airway along with mild fibrous thickening of the subepithelial layer in the airway exposed to OVA + B.ad 8 (F). Slight goblet cell proliferation and slight infiltration of inflammatory cells in the submucosa of airway exposed to OVA + H-ASD (G). Moderate goblet cell proliferation, numerous inflammatory cells in the submucosa of airway, and serious fibrous thickening of the subepithelial layer in the airway and macrophages scattered in alveoli exposed to OVA + H-ASD + B.ad 8 (H). (A-H) PAS stain; bar $=100 \mu \mathrm{m}$.

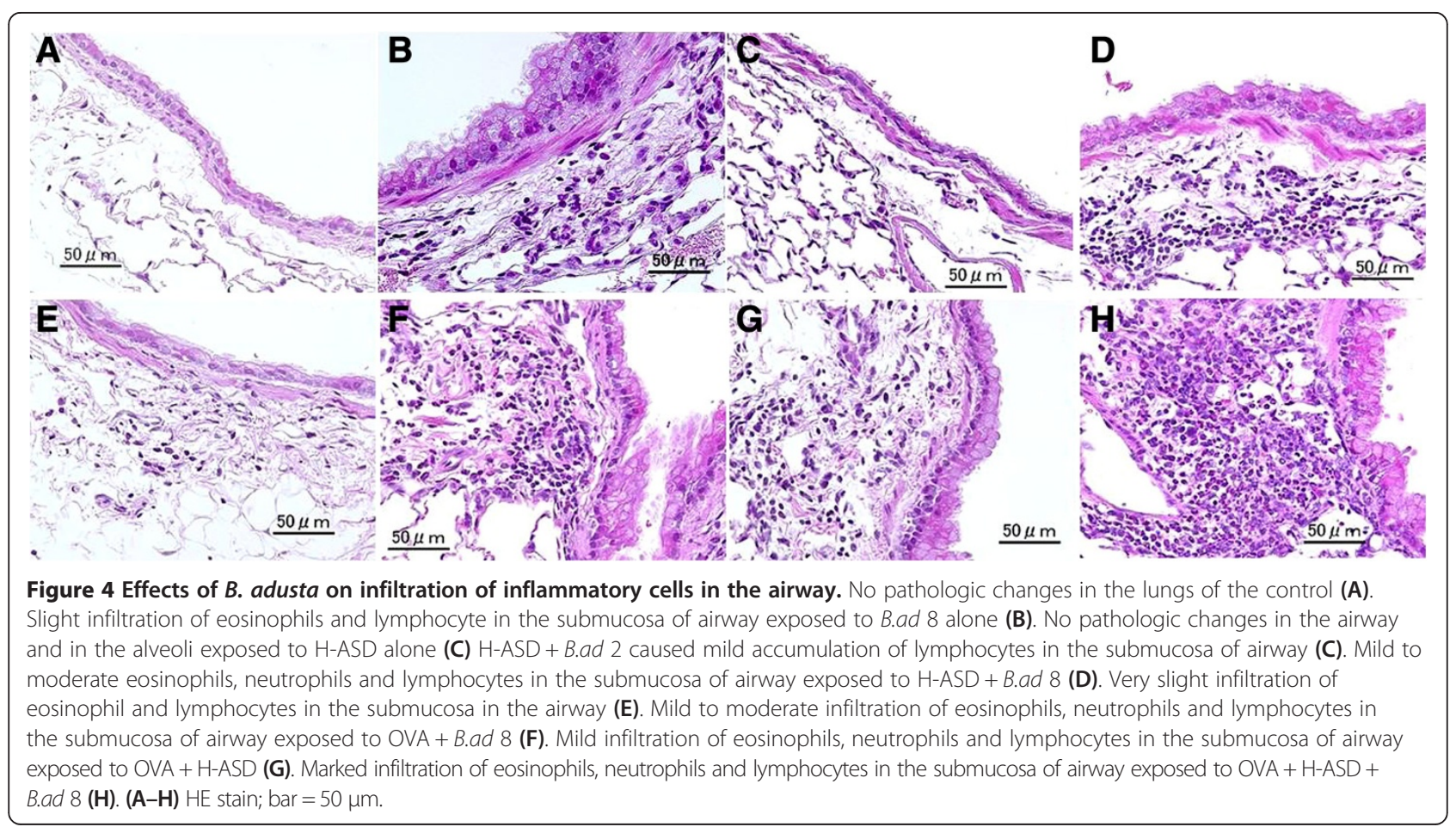


( $\mathrm{H}$ in Figure 3). Overall, $\mathrm{H}$-ASD played an important role in the enhancement of pathological changes.

\section{Enhancement of cytokines and chemokines in BALF by particle samples}

The protein levels of cytokines and chemokines determined in BALF are shown in Figures 5, 6, 7 and 8. As shown in Figure 5, B. adusta increased all proteins, in particular KC, determined in BALF with a dose relation. The mixture of H-ASD and B. adusta increased all proteins significantly. In particular, IL-12 increased 7-fold with the addition of B.ad 8 to H-ASD. A considerable increase of RANTES was also observed in this sample. In the case of the OVA treated groups, the addition of $B$. adusta also promoted an increase of these proteins, in particular KC. When B.ad 8 was added to an OVA $+\mathrm{H}-$ ASD sample, IL-12 and MCP-1 increased remarkably compared with samples treated with OVA alone. On the other hand, addition of OVA to H-ASD + B. adusta sample decreased IL-12, MCP-1 and RANTES, suggesting that OVA inhibits their activity.

Figure 6 shows the expression of IL- $1 \beta$, IL- 6 , TNF- $\alpha$, and MIP- $1 \alpha$ in BALF. OVA alone did not exhibit any appreciable activity. H-ASD showed moderate effects of an increase of proteins, of which MIP- $1 \alpha$ was the most affected. An increase of MIP- $1 \alpha$ was also observed in the case of OVA + H-ASD. Obvious increases of all proteins with a dose relation were obtained by the presence of $B$. adusta. It is obvious that $B$. adusta plays an important role in the increase of these proteins. In particular, B.ad 8 alone clearly increased IL- $1 \beta$ and TNF- $\alpha$ compared with the control group. Overall, the addition of $B$. adusta to H-ASD and OVA samples increased proteins markedly. Generally, the presence of OVA decreased proteins. For example, the addition of OVA to H-ASD removed TNF- $\alpha$ completely.

Figure 7 shows the expression of IL-5, IL-13, Eotaxin, and MCP-3 in BALF. Only trace levels of MCP-3 were detected in the control groups. H-ASD and OVA alone did not increase any proteins analyzed in BALF. B. $a d u$ sta alone increased levels of proteins slightly. On the other hand, a mixture of H-ASD or OVA with $B$. adusta clearly increased the levels of proteins. H-ASD + B.ad 8 notably increased IL-13 and Eotaxin compared with the control and H-ASD alone. In the OVA treated groups, OVA + B.ad 8 considerably increased IL-5 compared to the control and OVA-only groups. OVA $+\mathrm{H}-\mathrm{ASD}+B$. adusta markedly increased all proteins with a dose relation compared with all other samples.

Figure 8 shows the expression of TGF- $\beta 1$ and IL-10 in BALF. No proteins were detected in the samples from control, B. adusta alone, OVA alone, and OVA $+\mathrm{H}$ -

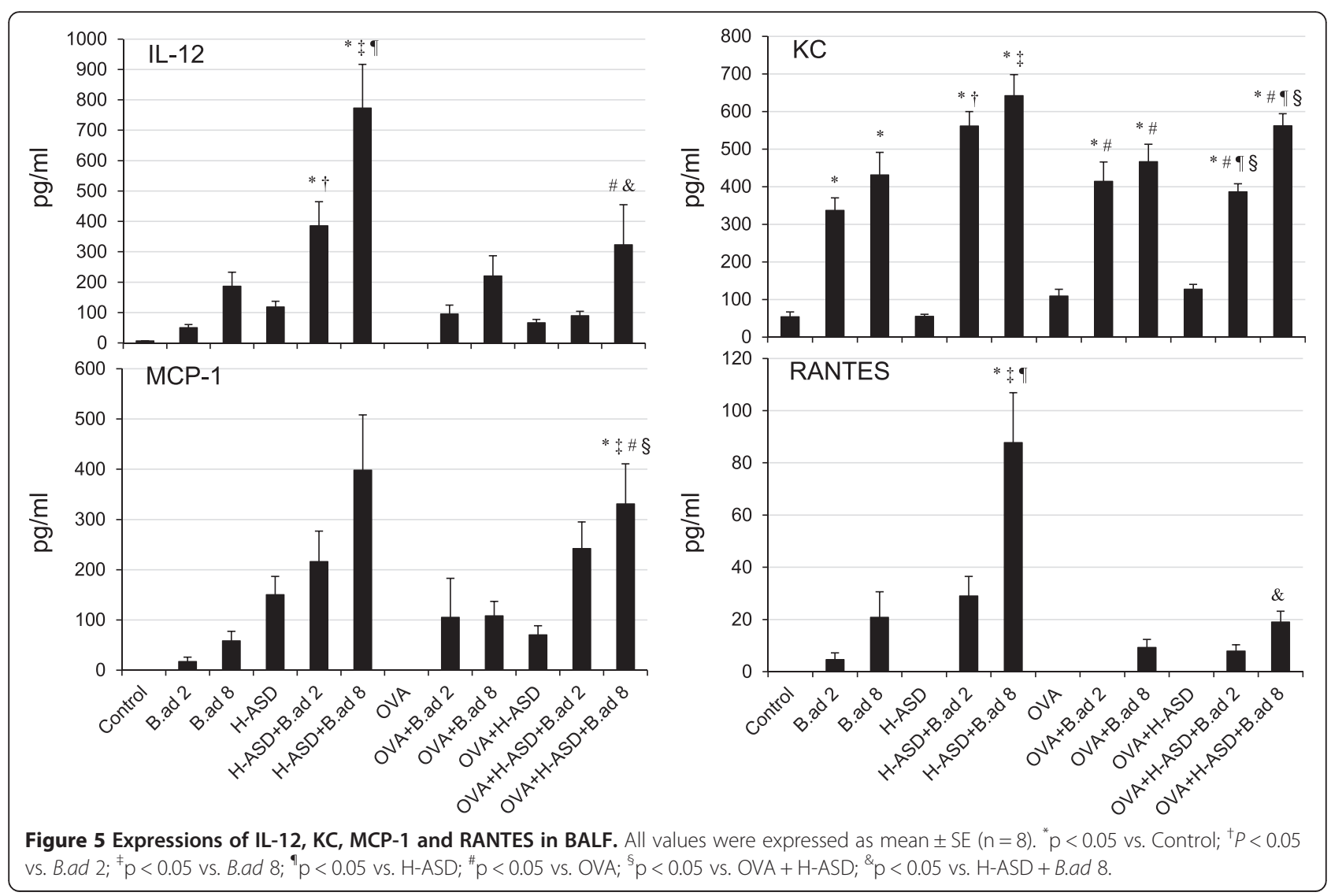




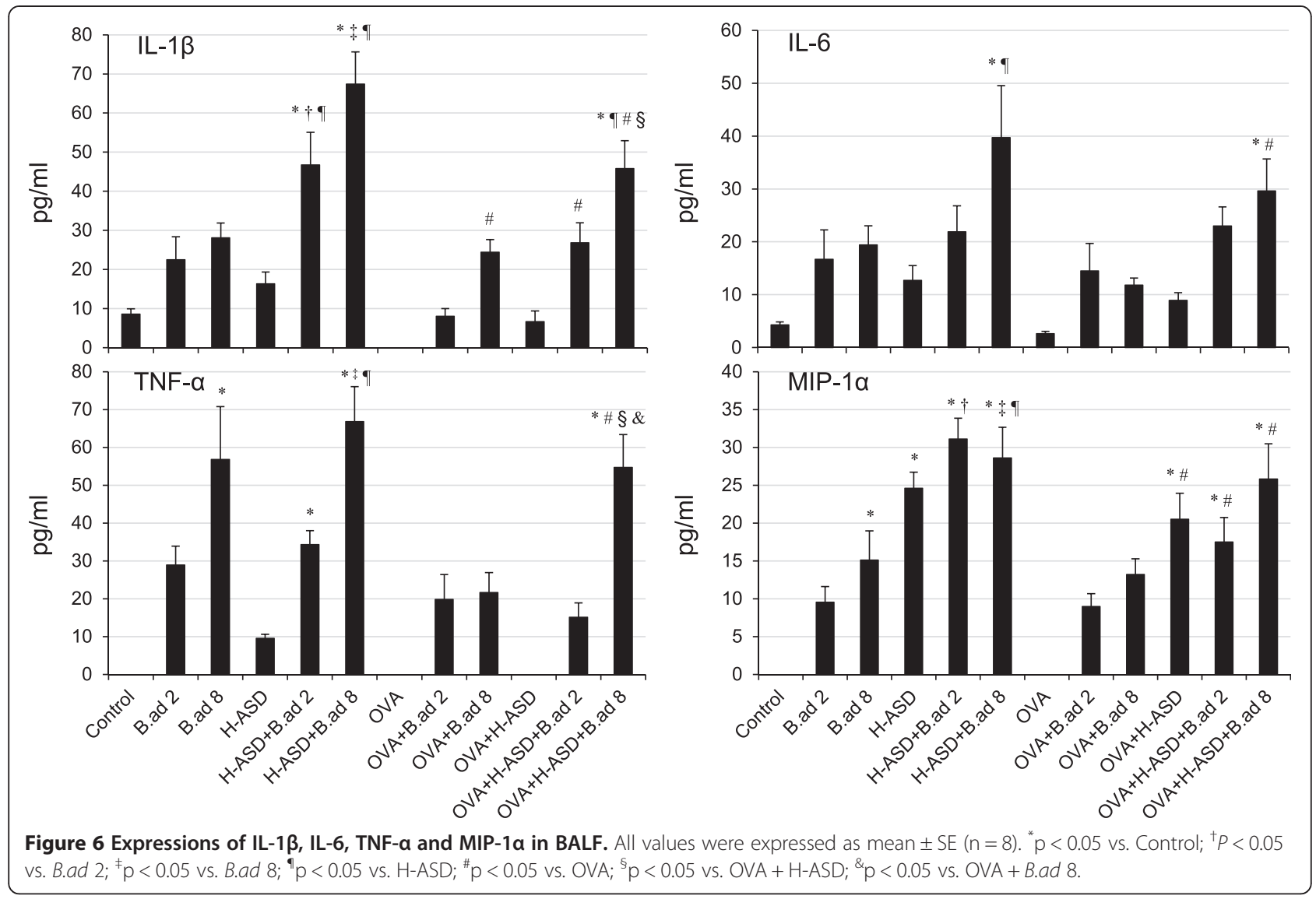

ASD. An obvious increase of TGF- $\beta 1$ was observed in the BALF from the groups treated with mixtures of $\mathrm{H}$ ASD and B.ad 8. In the OVA treated groups, the addition of B.ad 8 increased TGF- $\beta 1$ and IL- 10 moderately compared with the groups treated with OVA alone. $\mathrm{OVA}+\mathrm{H}-\mathrm{ASD}+\mathrm{B}$. adusta markedly increased TGF- $\beta 1$ with a dose relation compared with all other samples. The significant increase of IFN- $\gamma$, IL- 4 and IL-33 was not detected in this study.

Figure 9 shows the expression of OVA-specific IgG1 in serum. OVA + H-ASD + B.ad 2/B.ad 8 increased IgG1 compared with OVA alone. However, no induction of OVA-specific IgE was observed in any of these groups.

\section{Discussion}

It is known that ASD aerosol contains many kinds of microorganisms $[5,14]$. B. adusta, isolated from the windborne ASD aerosol, may affect FACC or asthmatic patients negatively. In the present study, the exacerbating effects of ASD on $B$. adusta-induced lung inflammation and the exacerbating effects of the fungus and ASD on ovalbumin (OVA)-induced lung eosinophilia in a mouse model of asthma were examined. B. adusta is a mushroom fungus that grows in fields and colonizes rotting wood. The fungus, white-rot fungus, secretes multiple lignin peroxidase isozymes $[15,16]$ and has been applied for the biodegradation of polycyclic aromatic hydrocarbons [17], synthetic dyes [18], and synthetic polymer nylon [19] in agricultural fields.

This study demonstrated that the formalin-inactivated fungus causes lung eosinophilia in mice. The inactivated B. adusta alone dose relatively increased neutrophils and eosinophils along with proinflammatory mediators MIP$1 \alpha, \mathrm{KC}$ and TNF- $\alpha$ in BALF. Pathologically, the fungus caused eosinophil recruitment in the submucosa of the airway along with proliferation of goblet cells in the bronchial epithelium, suggesting that it acts as an antigen for human asthma. The treatment of inactivated B.adusta with H-ASD caused further increases in inflammatory cell numbers, pro-inflammatory cytokines (IL-1 $\beta$, IL-5, IL-6, IL-12, IL-13), and chemokines (Eotaxin, RANTES, MIP- $1 \alpha, \mathrm{KC}, \mathrm{MPC}-1, \mathrm{MCP}-3$ ) in BALF. The pathological changes in the airway induced by the co-treatment were more remarkable than $B$. adusta treatment alone, suggesting that H-ASD enhances B.adusta-induced lung eosinophilia via remarkable increases of these pro-inflammatory mediators, especially eosinophil-relevant chemokine MCP-3, cytokine IL-5 and Th2-mediated cytokine IL-13. Eosinophils are reportedly implicated in tissue destruction in 

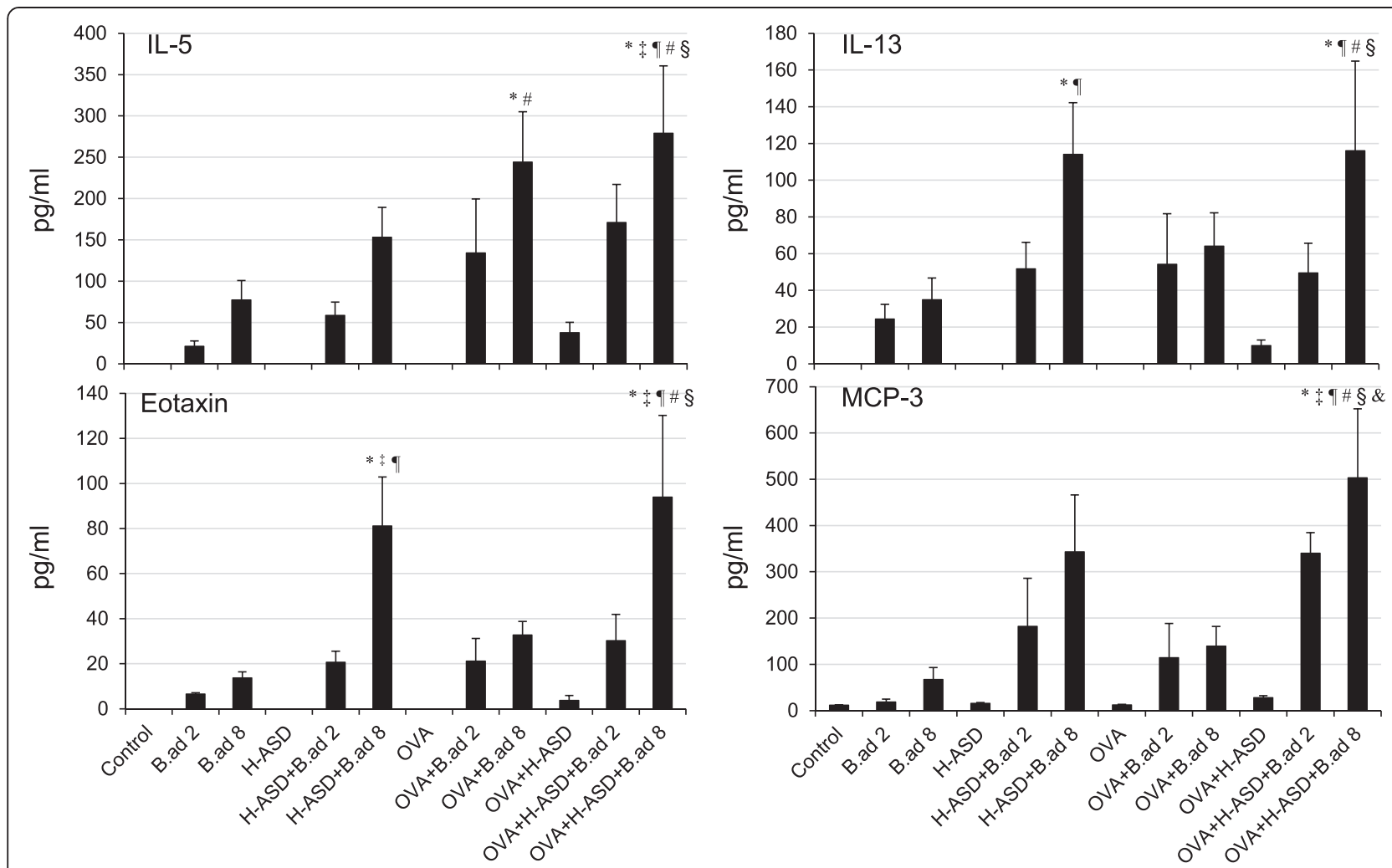

Figure 7 Expressions of IL-5, IL-13, Eotaxin and MCP-3 in BALF. All values were expressed as mean $\pm \mathrm{SE}(\mathrm{n}=8) .{ }^{*} \mathrm{p}<0.05 \mathrm{vs}$. Control; ${ }^{\dagger} P<0.05$ vs. B.ad 2; ${ }^{\ddagger} p<0.05$ vs. B.ad $8 ;{ }^{\natural} p<0.05$ vs. H-ASD; ${ }^{\#} p<0.05$ vs. OVA; ${ }^{\S} p<0.05$ vs. OVA + H-ASD; ${ }^{\circledR} p<0.05$ vs. OVA + B.ad 8.

allergic asthma [20]. Because, toxic eosinophil-derived proteins cause bronchial mucosal damage in asthmatic airways, they may exacerbate the symptoms of asthma [21]. IL-13 has been shown to stimulate B cells and subsequently produce antigen specific antibodies [22]. It also promotes mucous secretion and the production of mucous cells, such as goblet cells, in the bronchial epithelium [23]. Therefore, the airway injury resulting from co-treatment may be due to enhancement of eosinophilic airway-inflammation.

The pathway related to NF- $\mathrm{kB}$ activation by $\beta$-glucan reportedly indicated an association between TLR2 and

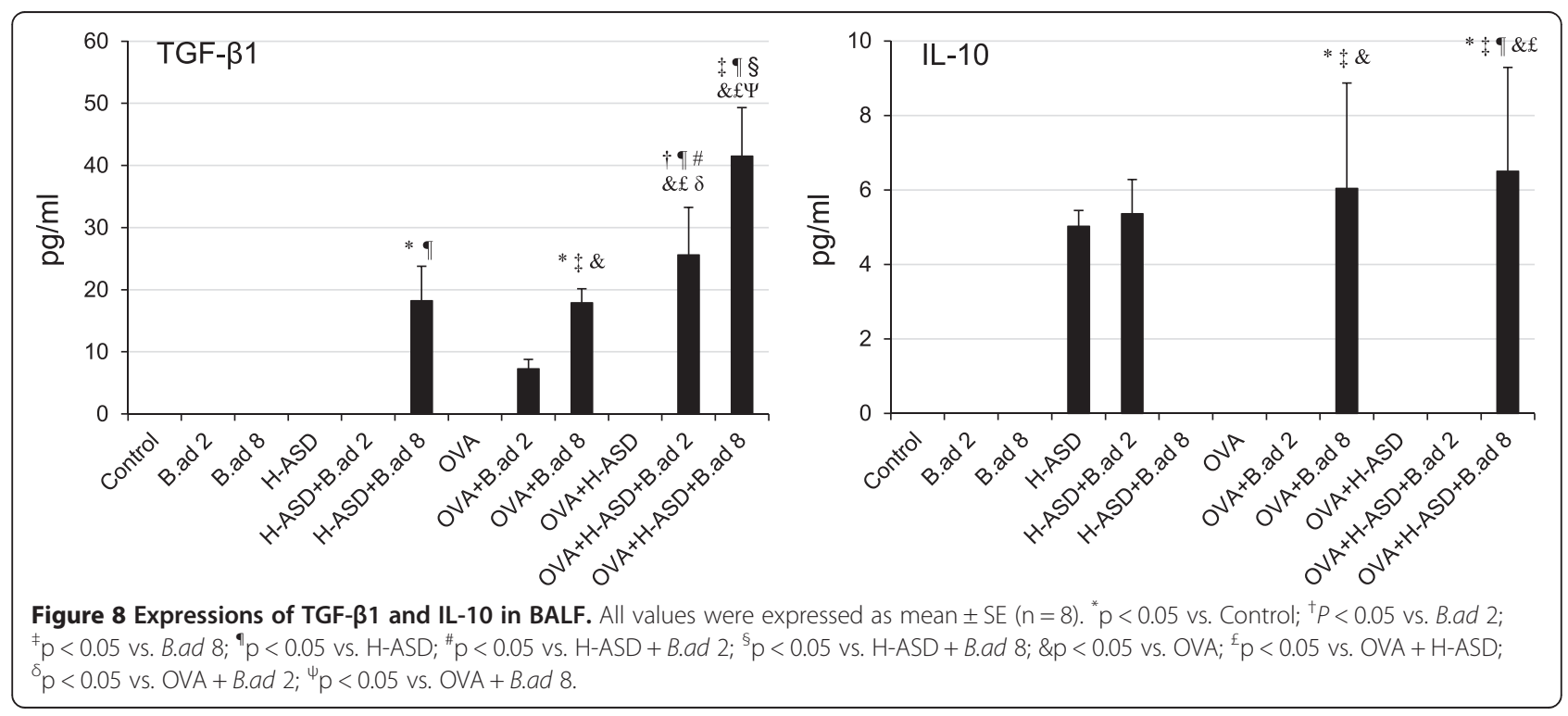




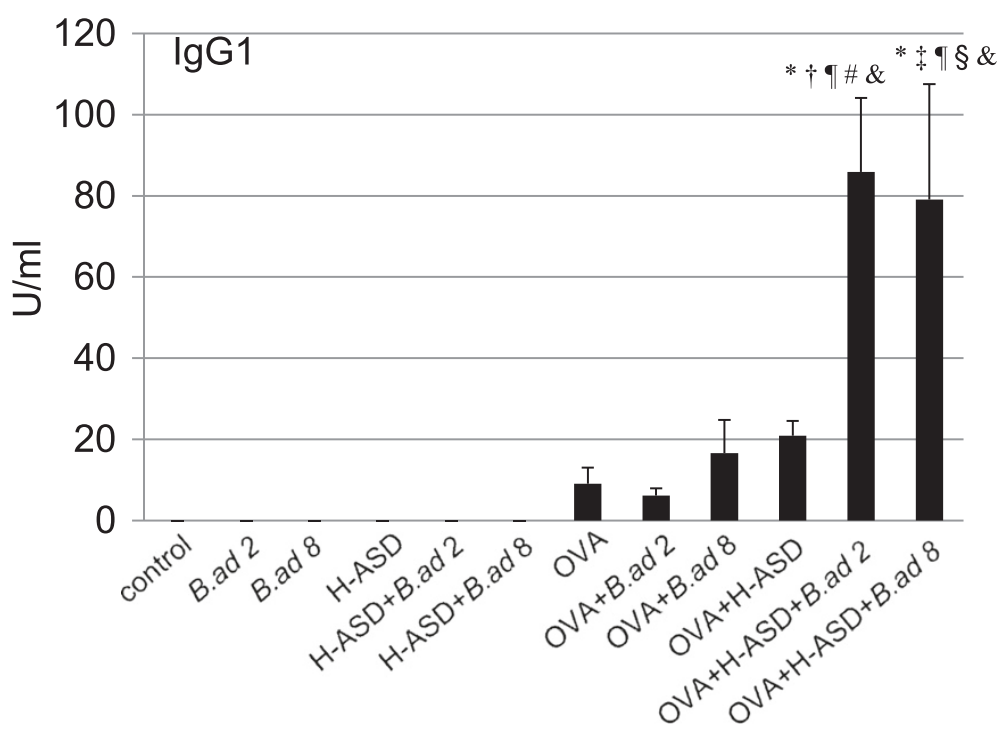

Figure 9 Effects of testing samples on IgG1 production in serum. According to the manufacturer's protocol, $1 \mathrm{U}$ of the anti-OVA IgG1 is defined as $160 \mathrm{ng}$ of the antibody. All values were expressed as mean \pm SE. ${ }^{*} p<0.05$ vs. Control; ${ }^{\dagger} p<0.05$ vs. B.ad 2; ${ }^{\neq} p<0.05$ vs. B.ad 8 ; ${ }^{9} p<0.05$ vs. H-ASD; ${ }^{\#} \mathrm{p}<0.05$ vs. H-ASD + B.ad $2 ;{ }^{\S} \mathrm{p}<0.05$ vs. H-ASD + B.ad $8 ;{ }^{\&} \mathrm{p}<0.01$ vs. OVA.

Dectin-1 [24]. In fact, the presence of trace $\beta$-glucan (32.8 ng/mg) in B. adusta was detected using a kinetic assay in the present study. Therefore, it is proposed that the aggravation by $\mathrm{H}$-ASD is due to the activation of TLR2-Dectin1-NF-kB signaling pathway that subsequently causes the production of inflammatory cytokines. However, the present study does not provide sufficient evidence to determine the role of $\beta$-glucan in allergic reactions.

In the case of the OVA treated groups, the addition of B. adusta increased eosinophil numbers along with their relevant cytokines and chemokines (Figure 7). Similar results were observed for neutrophil numbers and their relevant pro-inflammatory mediators (Figure 5). The asthma-like alterations induced in the airway by $B$. adusta with OVA were much higher than by treatment with B. adusta alone. Previous reports have demonstrated that co-treatment of TLR2-ligand Pam3Cys and OVA activates an OVA-associated Th2-biased immune response in experimental asthma [25]. These results suggest that $B$. adusta with $\beta$-glucan activates an OVArelated Th2-biased immune response through TLR2dependent signaling pathways. The addition of H-ASD also enhanced Th2-biased immune response in the present study. The results are consistent with a previous study [14]. When mice were treated with OVA + H-ASD + $B$. adusta, serious fibrous thickening of the subepithelial layer, eosinophil infiltration, and proliferation of goblet cells in the airway along with remarkable increases of Th2 cytokine IL-13 and eosinophil relevant cytokines and chemokines induced in BALF were observed
(Figure 7). Thus, allergen-induced asthma-like features must be more aggravated by $\mathrm{H}-\mathrm{ASD}+B$. adusta .

Addition of OVA to a particle sample consisting of $\mathrm{H}$ ASD and B. adusta increased TGF- $\beta$ (Figure 8). TGF- $\beta 1$ is well known to possess various biological activities including immunosuppression [26]. However, the suppressive effects on the Th2 response as result of an increase of TGF- $\beta$ was not detected in this study.

In addition, TGF- $\beta 1$ is also well known as a repair and profibrotic cytokine [27]. Hyperplasia of bronchial structural cells, like fibroblasts and smooth muscle cells in the airway, is a typical feature of airway remodeling. The induction levels of TGF- $\beta 1$ in the present study paralleled the severity of fibrous thickening of the subepithelial layer in the airway. Therefore, TGF- $\beta 1$ may play an important role in the development of serious fibrous thickening (airway remodeling) in this experimental asthma, especially in the OVA + H-ASD + B.ad 8 treated groups.

IL-10 produced by Treg cells or Type 1 regulatory $\mathrm{T}$ (Tr1) cells also suppresses the Th2 cell-driven response to allergens, as does TGF- $\beta 1[28,29]$. However, the suppressive effect to Th2 response by an increase of IL-10 in the OVA + B.ad 8 and OVA + H-ASD + B.ad 8 treated groups was not detected.

In the present study, an adjuvant effect of $B$. adusta and H-ASD toward OVA-specific IgG1 production was detected but OVA-specific IgE production was not (Figure 9). Antigen-specific IgG1 can cause degranulation via an Fcg RII receptor on the eosinophil's surface [30]. Therefore, antibodies may play an important role in 
the aggravation of lung eosinophilia caused by OVA $+\mathrm{H}-$ $\mathrm{ASD}+$ B.ad

\section{Conclusions}

B. adusta isolated from ASD aerosol caused murine lung eosinophilia and heat-treated ASD (H-ASD) aggravated the lung eosinophilia associated with $B$. adusta. B. adusta aggravated OVA-induced lung eosinophilia. A mixture of B. adusta, H-ASD, and OVA caused the most remarkable exacerbation to the allergic airway inflammation in experimental animals. Therefore, the present study indicates that $B$. adusta is an allergic exacerbating factor and acts as an inducer of eosinophilic lung disease and that $\mathrm{H}$-ASD is an allergic exacerbating factor.

The adverse effects of dust containing minerals and biogenic agents on human respiratory diseases have become a public concern. In particular, atmospheric exposure to fungi, bacteria, and silica-carrying particulate matters may affect human health directly through allergic induction of respiratory stress. Therefore, the results obtained in the present study may serve as a warning about the ill effects of airborne sand dust on the human respiratory system and also be useful in finding the appropriate method for treating patients with FACC or asthma. In order to clarify an association of ASD events with the exacerbation of FACC or asthma, epidemiological study is in order.

\section{Abbreviations \\ ASD: Asian sand dust; B. adusta: Bjerkandera adusta; OVA: Ovalbumin; BALF: Bronchoalveolar lavage fluid; ELISA: Enzyme-linked immunosorbent assays; FACC: Fungi in fungus-associated chronic cough; H-ASD: Heated Asian sand dust; IFN-ү: Interferon- $\gamma ;$ IL: Interleukin; KC: Keratinocyte chemoattractant; MCP-1: Monocyte chemotactic protein-1; MCP-3: Monocyte chemotactic protein-3; MIP-1a: Macrophage inflammatory protein-1a; NF- kB: Nuclear factor-kappa B; RANTES: Regulated on activation normal T cell expressed and presumably secreted; TGF- $\beta 1$ : Transforming growth factor- $\beta 1$; TLR: Toll like receptor; TNF-a: Tumor necrosis factor-a.}

\section{Competing interests}

The authors do not have any conflicts of interest to disclose.

\section{Authors' contribution}

TI designed the research. BL, MH, FK, MT, SY, YY, KA, HT, and MN conducted the experiments. TI and TS analyzed the data and wrote the manuscript. TI and GS had primary responsibility for final content. All authors read and approved the final manuscript.

\section{Acknowledgments}

This study was supported in part by grants from the Ministry of Education, Culture, Sports, Science and Technology of Japan (No. 22241011) and the Global Environment Research Fund of the Ministry of the Environment Japan (C-1155). We appreciate the vital contribution of students at Oita University of Nursing and Health Sciences in this research.

\section{Author details}

'Environment and Chronic Non-communicable Disease Research Center, College of Public Health, China Medical University, 11001 Shenyang, China. ${ }^{2}$ Department of Health Sciences, Oita University of Nursing and Health Sciences, 870-1201 Oita, Japan. ${ }^{3}$ College of Science and Engineering, Kanazawa University, 920-1192 Ishikawa, Japan. ${ }^{4}$ Department of Immunology and Parasitology, School of Medicine, University of Occupational and
Environmental Health, Japan, 807-8555 Fukuoka, Japan. ${ }^{5}$ Environmental Health Division, Department of Environmental Engineering, Graduate School of Engineering, Kyoto University, 615-8530 Kyoto, Japan. ${ }^{6}$ Environmental Chemistry Division, National Institute for Environmental Studies, 305-8506 Ibaraki, Japan. ${ }^{7}$ Department of Environmental Toxicology, University of California, Davis, CA 95616, USA. ${ }^{8}$ Present address: Department of Prophylaxis and Health Care, The Fourth Affiliated Hospital of China Medical University, 110032 Shenyang, China.

Received: 16 November 2013 Accepted: 30 January 2014

Published: 5 February 2014

\section{References}

1. Ogawa H, Fujimura M, Takeuchi Y, Makimura K: Is Bjerkandera adusta important to fungus-associated chronic cough (FACC) as an allergen? Eight cases' report. J Asthma 2009, 46:849-855.

2. Ogawa H, Fujimura M, Takeuchi Y, Makimura K, Satoh K: Sensitization to Bjerkandera adusta enhances severity of cough symptom in patients with fungus-associated chronic cough (FACC). Med Mycol I 2011, 52(3):205-212

3. Duce RA, Unni CK, Ray BJ, Prospero JM, Merrill JT: Long-range atmospheric transport of soil dust from Asia to the tropical north pacific: temporal variability. Science 1980, 209:1522-1524

4. Kim BG, Han JS, Park SU: Transport $\mathrm{SO}_{2}$ and aerosol over the Yellow Sea. Atmos Environ 2001, 35:727-737.

5. Kobayashi F, Kodanikuchi K, Kakikawa M, Maki T, Yamada M, Tobo Y, Hong CS, Matsuki A, Iwasaka Y: Direct samplings, separated culture, and identifications of kosa bioaerosols over Noto Peninsula, Suzu City (Japanese). Earozoru Kenkyu 2010, 25(1):23-28.

6. Kanatani KT, Ito I, Al-Delaimy WK, Adachi Y, Mathews WC, Ramsdell JW Toyama Asian Desert Dust, Asthma Study Team: Desert dust exposure is associated with increased risk of asthma hospitalization in children. Am J Respir Crit Care Med 2010, 182(12):1475-1481.

7. Watanabe M, Yamasaki A, Burioka N, Kurai J, Yoneda K, Yoshida A, Igishi T, Fukuoka Y, Nakamoto M, Takeuchi H, Suyama H, Tatsukawa T, Chikumi H, Matsumoto S, Sako T, Hasegawa Y, Okazaki R, Horasaki K, Shimizu E: Correlation between Asian dust storms and worsening asthma in western Japan. Allergol Int 2011, 60(3):267-275.

8. Ichinose T, Takano H, Sadakane K, Yanagisawa R, Kawazato H, Sagai M, Shibamoto T: Differences in airway-inflammation development by house dust mite and diesel exhaust inhalation among mouse strains. Toxicol Appl Pharmacol 2003, 187:29-37.

9. Maki T, Fukushima R, Kobayashi F, Yamada M, Hasegawa H, Iwasaka Y: Analysis of airborne-bacterial compositions using $16 \mathrm{~S}$ rDNA clone library technique. Bunseki Kagaku 2013, 62(12):1095-1104 (in Japanese).

10. Holtfreter S, Jursa-Kulesza J, Masiuk H, Verkaik NJ, de Vogel C, Kolata J, Nowosiad M, Steil L, van Wamel W, van Belkum A, Völker U, GiedrysKalemba S, Bröker BM: Antibody responses in furunculosis patients vaccinated with autologous formalin-killed Staphylococcus aureus. Eur J Clin Microbiol Infect Dis 2011, 30(6):707-717.

11. Maki T, Susuki S, Kobayashi F, Kakikawa M, Yamada M, Higashi T, Chen B Shi G, Hong C, Tobo Y, Hasegawa H, Ueda K, Iwasaka Y: Phylogenetic diversity and vertical distribution of a halobacterial community in the atmosphere of an Asian dust (KOSA) source region, Dunhuang City. Air Qual Atmos Health 2008, 1:81-89.

12. He M, Ichinose T, Yoshida S, Takano H, Nishikawa M, Mori I, Sun G, Shibamoto T: Aggravating effects of Asian sand dust on lung eosinophilia in mice immunized beforehand by ovalbumin. Inhal Toxicol 2012, 24(11):751-761.

13. He M, Ichinose T, Yoshida S, Takano H, Nishikawa M, Sun G, Shibamoto T: Induction of immune tolerance and reduction of aggravated lung eosinophilia by co-exposure to Asian sand dust and ovalbumin for 14 weeks in mice. Allerg Asthma Clin Immunol 2013, 9:19-29.

14. Maki T, Susuki S, Kobayashi F, Kakikawa M, Tobo Y, Yamada M, Higashi T, Matsuki A, Hong C, Hasegawa H, Iwasaka Y: Phylogenetic analysis of atmospheric halotolerant bacterial communities at high altitude in an Asian dust (KOSA) arrival region, Suzu City. Sci Total Environ 2010, 408(20):4556-4562

15. Wang Y, Vazquez-Duhalt R, Pickard MA: Effect of growth conditions on the production of manganese peroxidase by three strains of Bjerkandera adusta. Can J Microbiol 2001, 47(4):277-282. 
16. Kimura Y, Asada Y, Oka T, Kuwahara M: Molecular analysis of a Bjerkandera adusta lignin peroxidase gene. Appl Microbiol Biotechnol 1991, 35(4):510-514

17. Field JA, de Jong E, Feijoo Costa G, de Bont JA: Biodegradation of polycyclic aromatic hydrocarbons by new isolates of white rot fungi. Appl Environ Microbiol 1992, 58:2219-2226.

18. Heinfling A, Martinez MJ, Martinez AT, Bergbauer M, Szewzyk U: Transformation of industrial dyes by manganese peroxidases from Bjerkandera adusta and Pleurotus eryngii in a manganese-independent reaction. Appl Environ Microbiol 1998, 64:2788-2793.

19. Friedrich J, Zalar P, Mohorcic M, Klun U, Krzan A: Ability of fungi to degrade synthetic polymer nylon-6. Chemosphere 2007, 67(10):2089-2095.

20. Kidd P: Th1/Th2 balance: The hypothesis, its limitations, and implications for health and disease. Altern Med Rev 2003, 8:223-246.

21. Bradley BL, Azzawi M, Jacobson M, Assoufi B, Collins JV, Irani AM, Schwartz LB, Durham SR, Jeffery PK, Kay AB: Eosinophils, T-lymphocytes, mast cells, neutrophils, and macrophages in bronchial biopsy specimens from atopic subjects with asthma: comparison with biopsy specimens from atopic subjects without asthma and normal control subjects and relationship to bronchial hyperresponsiveness. J Allergy Clin Immunol 1991, 88(4):661-674.

22. Mosmann TR, Coffman RL: TH1 and TH2 cells: Different patterns of lymphokine secretion lead to different functional properties. Annu Rev Immunol 1989, 7:145-173.

23. Tesfaigzi Y: Regulation of mucous cell metaplasia in bronchial asthma. Curr Mol Med 2008, 8:408-415.

24. Shin DM, Yang CS, Yuk JM, Lee JY, Kim KH, Shin SJ, Takahara K, Lee SJ, Jo EK: Mycobacterium abscessus activates the macrophage innate immune response via a physical and functional interaction between TLR2 and dectin-1. Cell Microbiol 2008, 10(8):1608-1621.

25. Redecke V, Häcker H, Datta SK, Fermin A, Pitha PM, Broide DH, Raz E: Cutting edge: Activation of Toll-like receptor 2 induces a Th2 immune response and promotes experimental asthma. J Immunol 2004, 172:2739-2743.

26. Gorelik L, Flavell RA: Transforming growth factor-beta in T-cell biology. Nat Rev Immunol 2002, 2:46-53.

27. Bochner BS, Undem BJ, Lichtenstein LM: Immunological aspects of allergic asthma. Annu Rev Immunol 1994, 12:295-335.

28. Kearley J, Barker JE, Robinson DS, Lloyd CM: Resolution of airway inflammation and hyperreactivity after in vivo transfer of $\mathrm{CD} 4^{+} \mathrm{CD} 25^{+}$ regulatory T cells is interleukin 10 dependent. J Exp Med 2005, 202(11):1539-1547.

29. Wu K, Bi Y, Sun K, Wang C: IL-10-producing type 1 regulatory T cells and allergy. Cell Mol Immunol 2007, 4(4):269-275.

30. Kaneko M, Swanon MC, Gleich GJ, Kita H: Allergen-specific lgG1 and IgG3 through Fc g Rll induce eosinophil degranulation. J Clin Invest 1995, 95(6):2813-2821.

doi:10.1186/1710-1492-10-10

Cite this article as: Liu et al.: Lung inflammation by fungus, Bjerkandera adusta isolated from Asian sand dust (ASD) aerosol and enhancement of ovalbumin-induced lung eosinophilia by ASD and the fungus in mice. Allergy, Asthma \& Clinical Immunology 2014 10:10.

\section{Submit your next manuscript to BioMed Central and take full advantage of:}

- Convenient online submission

- Thorough peer review

- No space constraints or color figure charges

- Immediate publication on acceptance

- Inclusion in PubMed, CAS, Scopus and Google Scholar

- Research which is freely available for redistribution

Submit your manuscript at www.biomedcentral.com/submit
Ciomed Central 